\title{
Growth Kinetic Effects on MAX Phase Thin-Films Microstructure
}

\author{
Brenet F, Furgeaud C, Nicolai J* \\ Institut Pprime, UPR 3346, Université de Poitiers, France \\ *Corresponding author: J Nicolai, Institut Pprime, UPR 3346, Université de Poitiers, France
}

\begin{abstract}
In this paper, $\mathrm{Ti}_{3} \mathrm{SiC}_{2}, \mathrm{Ti}_{3} \mathrm{AlC}_{2}$ and $\mathrm{Ti}_{2} \mathrm{AlC}$ thin films were synthesized using a two-step method consisting on TiAl ${ }_{2}$ magnetron sputtering deposition and post-deposited annealing at $800^{\circ} \mathrm{C}$ or $1000^{\circ} \mathrm{C}$. X-ray Diffraction (XRD) and Transmission Electron Microscopy (TEM) were used for the phase identification and microstructure studies. We focused on the kinetic effect of MAX phase growth influenced by annealing time of one and several runs. The results obtained show that for one annealing during $30 \mathrm{~min}$ we synthesized $\mathrm{Ti}_{3} \mathrm{AlC}_{2}$ or $\mathrm{Ti}_{3} \mathrm{SiC}_{2}$ respectively for $800^{\circ} \mathrm{C}$ and $1000^{\circ} \mathrm{C}$. Although the total thermal energy provided by annealing steps is equal in each case, one annealing run leads to a very pure $312 \mathrm{MAX}$ phase $\left(\mathrm{Ti}_{3} \mathrm{AlC}_{2}\right.$ at $800^{\circ} \mathrm{C}$ and $\mathrm{Ti}_{3} \mathrm{SiC}_{2}$ at $\left.1000^{\circ} \mathrm{C}\right)$, while the interruption during the annealing and the increase cooling step number for the same total annealing time leads to the $211 \mathrm{MAX}$ phase for $800^{\circ} \mathrm{C}$ and to a mix between $\mathrm{Ti}_{3} \mathrm{AlC}_{2}$ and $\mathrm{Ti}_{2} \mathrm{AlC}$ for $1000^{\circ} \mathrm{C}$.
\end{abstract}

Keywords: MAX phase; Thin films; Epitaxy; Magnetron sputtering; kinetic effect

\section{Introduction}

$M_{n+1} X_{n}$ phases ( $\left.n=1-3\right)$ consist in a large class of nanolaminated materials where $\mathrm{M}$ is an early transition metal element, $\mathrm{A}$ is an A-group element and $\mathrm{X}$ is either $\mathrm{C}$ or $\mathrm{N}$ [1-5]. For $\mathrm{n}=1,2,3$ the MAX phases are respectively called 211,312 and 413 due to the periodic arrangement of their structure: $\mathrm{n} \mathrm{M}_{6} \mathrm{X}$ octahedrons separated by a layer of A element in a hexagonal structure. This particular structure gives to the MAX phases a unique combination of metal and ceramic properties, opening the way to a large field of applications $[6,7]$. The $\mathrm{Ti}_{3} \mathrm{SiC}_{2}$ and $\mathrm{Ti}_{2} \mathrm{AlC}$ MAX phases have been extensively studied due to their excellent properties, including irradiation resistance [8-10], oxidation resistance [11] and electrical properties [12,13]. Several different techniques have been used to synthesize bulk MAX phases. Among these techniques, the most widespread is hot isostatic pressing (HIP) [14] however, various techniques have been developed for the growth of MAX phase thin films using magnetron sputtering technology, either from elemental targets or from compound targets on various substrates $[15,16]$. As shown on our recent papers, the co-deposition of $\mathrm{Ti}$ and $\mathrm{Al}$ on SiC-4H substrates leads, depending on annealing conditions, to the formation of either $\mathrm{Ti}_{3} \mathrm{SiC}_{2}$ or $\mathrm{Ti}_{2} \mathrm{AlC}$ [17]. Despite the huge number of studies achieved on MAX phases the formation mechanisms are not well-known. In this paper, we report on correlation between annealing process (temperature, run number, time of run) MAX phase kinetic growth.

\section{Materials and Methods}

SiC-4H substrates, single crystal (0001), n-type, supplied by TANKEBLUE, were used in this study. Al and Ti were co-deposited at room temperature onto $\mathrm{SiC}$ substrates by magnetron sputtering using pure $\mathrm{Al}$ (99.999\%) and $\mathrm{Ti}$ (99.995\%) targets in a high vacuum chamber (Figure 1), the Ar working pressure has been fixed at $0.3 \mathrm{~Pa}$. Before deposition, the substrate was in-situ cleaned by an etching at $60 \mathrm{~V}$ during 600s. As shown Figure 1 the fresh $\mathrm{TiAl}_{2}$ deposited layer is nanocrystalline. The samples were annealed in a vacuum lamp furnace (heating rate close to $20^{\circ} \mathrm{C} \mathrm{s}^{-1}$ ) at $800^{\circ} \mathrm{C}$ or $1000^{\circ} \mathrm{C}$ during one run of $30 \mathrm{~min}$ or 3 runs of $10 \mathrm{~min}$ for each temperature under a pressure around $10^{-5} \mathrm{~Pa}$. Composition and thin film thickness have been checked using X-ray reflectometry (3000 Seifert) and SEM techniques (JEOL 7001 TTLS). The structural 
investigations were performed by using X-Ray Diffraction (XRD) and Transmission Electron Microscopy (TEM). Diffraction experiments were conducted on a D8 Brucker AXS diffractometer operating in the Bragg-Brentano geometry under atmosphere environment. Diffractometer operates with a $\mathrm{Cu}$ tube and the $\mathrm{K} \beta$ radiation is absorbed by a Ni filter in order to obtain a pure $\mathrm{Cu} \mathrm{K} \alpha$ radiation $(\lambda=0.15418 \mathrm{~nm})$. The LynxEye detector is used for $\omega-2 \theta$ scans with a slight offset to avoid $\mathrm{SiC}$ reflections $\left(\omega-2 \theta=0.2^{\circ}\right)$. HighResolution TEM and Scanning Transmission Electron Microscopy (STEM) images were carried out using a JEOL 2200FS (SchottkyFEG, 200kV). TEM samples were prepared by Focused Ion Beam (FIB) using an FEI-HELIOS dual-beam using the standard lift-out method [18].
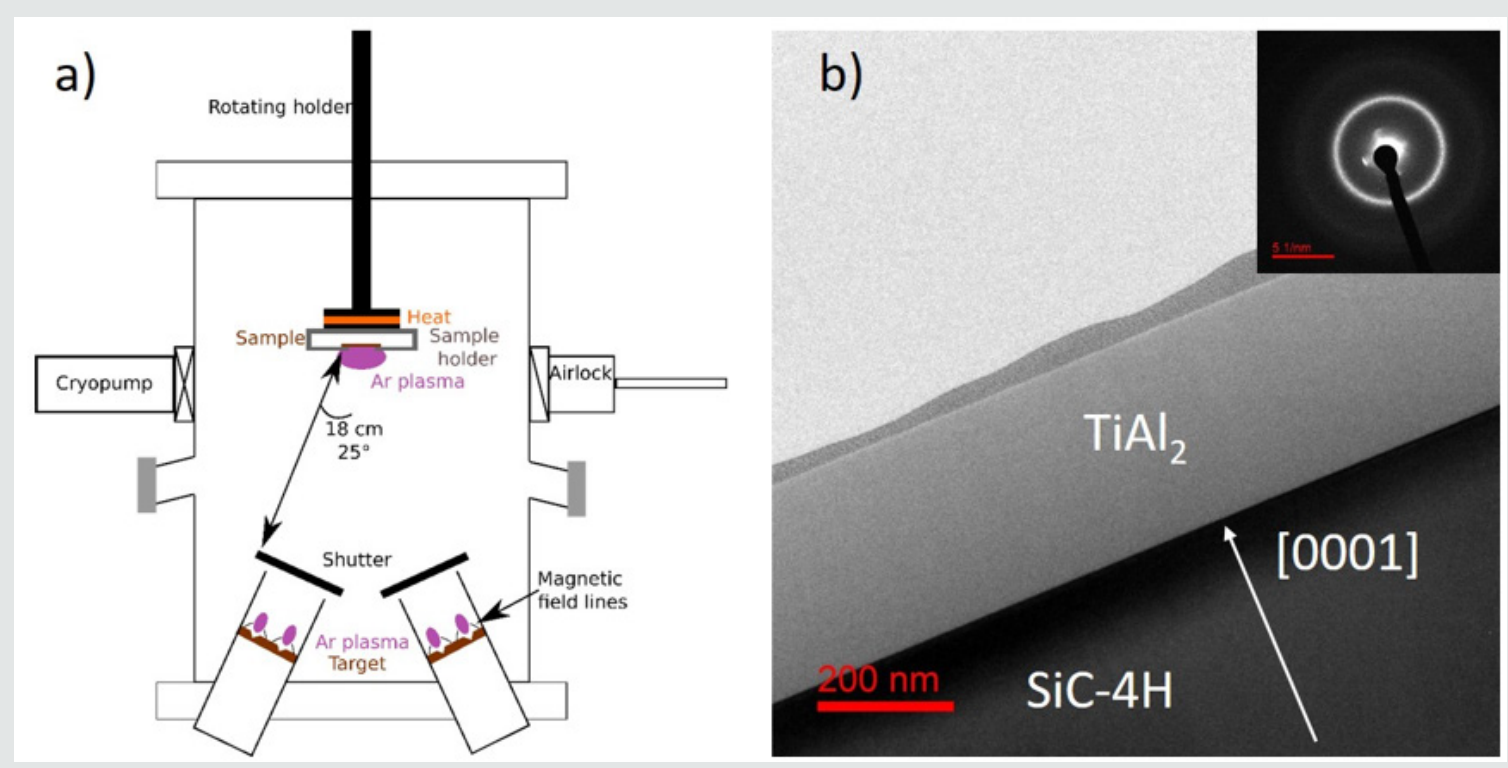

Figure 1: a) PUMA chamber scheme. b) TEM micrography of fresh of fresh $\mathrm{TiAl}_{2}$ deposited layer and associated diffraction pattern. The diffraction pattern clearly indicates the nanocrystalline structure of the $\mathrm{TiAl}_{2}$ layer.

\section{Results}

Figure 2 shows X-ray diffractograms of $\mathrm{TiAl}_{2}, 300 \mathrm{~nm}$ thick on $\mathrm{SiC}$ annealed at $800^{\circ} \mathrm{C} 1 \times 30 \mathrm{~min}$ and $3 \times 10 \mathrm{~min}$. Both diffractograms exhibit a peak at $39.2^{\circ}$ corresponding to (1014) reflection of the $\mathrm{Ti}_{3} \mathrm{AlC}_{2} \mathrm{MAX}$ phase structure. Moreover, the sample annealed during 1 x 30min shows exclusively $\mathrm{Ti}_{3} \mathrm{AlC}_{2} \mathrm{MAX}$ phase diffraction peaks, unlike the $3 \times 10 \mathrm{~min}$ sample also exhibits the (0002) and (0006) diffraction peaks of the $\mathrm{Ti}_{2} \mathrm{AlC}$ MAX phase respectively at $9.7^{\circ}$ and $39.7^{\circ}$. However, additional peaks could be observed and attributed to secondary phases. For 1 x $30 \mathrm{~min}$, peaks at $42.15^{\circ}$ and $42.71^{\circ}$ are attributed to (300) and (112) reflections of $\mathrm{Ti}_{5} \mathrm{Si}_{3}$. For $3 \times 10 \mathrm{~min}$ one peak at $46.0^{\circ}$ (not shown here) corresponds to (200) reflection of tetragonal $\mathrm{TiAl}_{2}$ phase and one peak at $42.7^{\circ}$ corresponds to the (112) reflections of $\mathrm{Ti}_{5} \mathrm{Si}_{3}$. The diffraction peak at $38.9^{\circ}$ corresponds to $\mathrm{SiC}-4 \mathrm{H}$ substrate. Figure 3 shows X-ray diffractograms of $\mathrm{TiAl}_{2} 300 \mathrm{~nm}$ thick on $\mathrm{SiC}$ annealed at $1000^{\circ} \mathrm{C}$ for both annealing strategies. For $1 \times 30 \mathrm{~min}$, we observed four peaks at $10.05^{\circ}, 20.12^{\circ}, 30.37^{\circ}$ and $40.82^{\circ}$ corresponding to (0002), (0004), (0006) and (0008) reflections of $\mathrm{Ti}_{3} \mathrm{SiC}_{2} \mathrm{MAX}$ phase. Moreover, the only secondary phase presents is the $\mathrm{Ti}_{5} \mathrm{Si}_{3}$ structure leading to (300) and (112) reflections at $42.15^{\circ}$ and $42.71^{\circ}$. The diffractogram of 3 $\mathrm{x} 10 \mathrm{~min}$ exhibits two peaks at $9.7^{\circ}$ and $39.2^{\circ}$ corresponding to the (0002) and (1014) of $\mathrm{Ti}_{3} \mathrm{AlC}_{2} \mathrm{MAX}$ phase, three peaks at $13.0^{\circ}, 39.7^{\circ}$ and $40.2^{\circ}$ corresponding to the (0002), (10i3) and (0006) of $\mathrm{Ti}_{2} \mathrm{AlC}$ MAX phase, one peak at $42.1^{\circ}$ corresponding to the (112) of $\mathrm{Ti}_{5} \mathrm{Si}_{3}$. Figure 4 shows the thin films obtained on $\mathrm{SiC}-4 \mathrm{H}$ for $\mathrm{TiAl}_{2}-300 \mathrm{~nm}$ after annealing at $800^{\circ} \mathrm{C}$ and $1000^{\circ} \mathrm{C}$ during $30 \mathrm{~min}$. The diffraction patterns obtained and the analysis of HRTEM micrographs reveal $\mathrm{Ti}_{3} \mathrm{AlC}_{2}$ and $\mathrm{Ti}_{3} \mathrm{SiC}_{2} \mathrm{MAX}$ phase thin film structure consistent with XRD investigations. Moreover the MAX phases grows in epitaxy with $\mathrm{SiC}-4 \mathrm{H}$ following the relation (0001)MAX // (0001)SiC and $[12 \overline{10}] \mathrm{MAX} / /[12 \overline{10}] \mathrm{SiC}$. The samples corresponding to $800^{\circ} \mathrm{C}$ and $1000^{\circ} \mathrm{C}$ annealed during $3 \times 10 \mathrm{~min}$ (not shown here) exhibit the same epitaxial relationship between the substrate and the layer formed at the interface. However, considering the $1000^{\circ} \mathrm{C}$ sample the MAX phase isn't $\mathrm{Ti}_{3} \mathrm{SiC}_{2}$ anymore but $\mathrm{Ti}_{3} \mathrm{AlC}_{2}$. STEM micrography (Figure 5) clearly indicates the presence of two different structures in the MAX phase layer. Measured spacing between atomic planes are $1.8 \mathrm{~nm}$ for the interfacial layer and 1.3 $\mathrm{nm}$ for the upper layer respectively corresponding to the 312 and 211 MAX phases. As observed on STEM micrographs, all films, whatever kind of MAX phases synthesized, are very flat (Figure 6) and exhibits a very good crystallinity (high chemical homogeneity and almost monocrystalline). The total thickness of the stacking of MAX phase are closed to $30 \mathrm{~nm}$ and $40 \mathrm{~nm}$ respectively for $800^{\circ} \mathrm{C}-3$ $\mathrm{x} 10 \mathrm{~min}$ and $1 \mathrm{x} 30 \mathrm{~min}$ and closed to $80 \mathrm{~nm}$ and $150 \mathrm{~nm}$ respectively for $1000^{\circ} \mathrm{C}-3 \times 10 \mathrm{~min}$ and $1 \times 30 \mathrm{~min}$. 


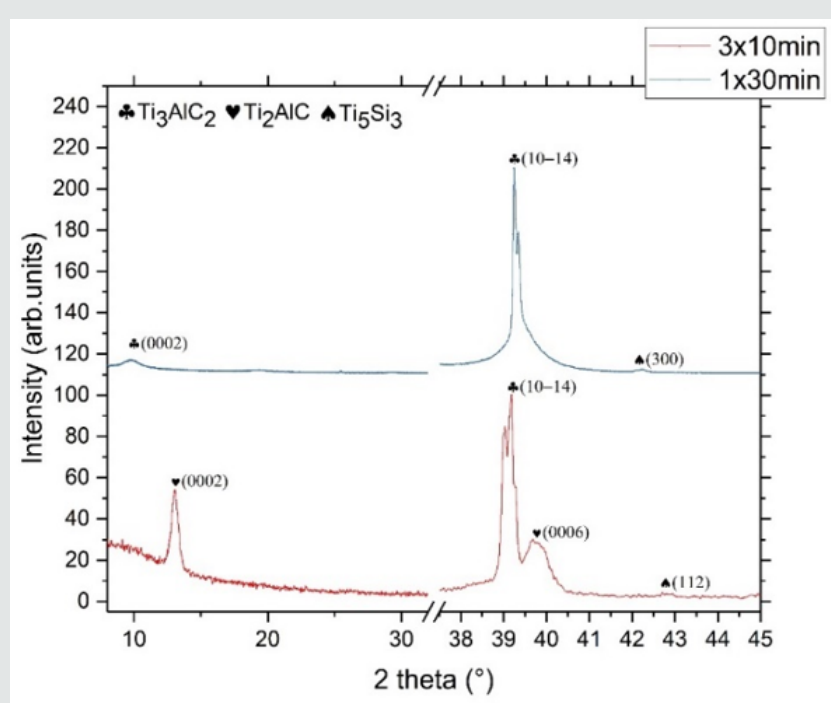

Figure 2: $\omega-2 \theta$ XRD diffractograms of $\mathrm{TiAl}_{2}-300 \mathrm{~nm}$ thick onto $4 \mathrm{H}-\mathrm{SiC}$ annealed at $800^{\circ} \mathrm{C}$ during $1 \times 30 \mathrm{~min}$ and $3 \times 10 \mathrm{~min}$.

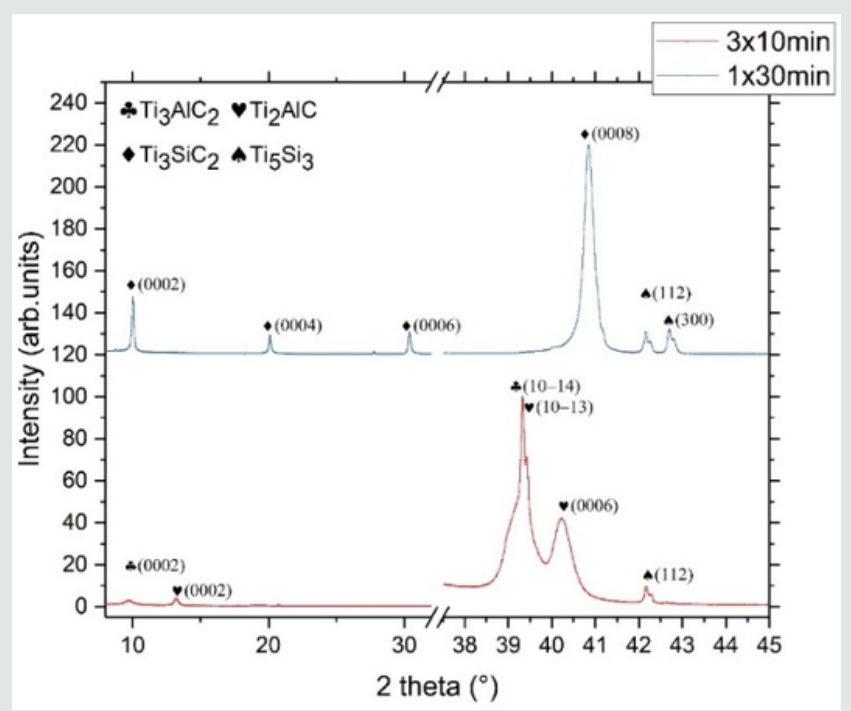

Figure 3: $\omega-2 \theta$ XRD diffractograms of $\mathrm{TiAl}_{2}-300 \mathrm{~nm}$ thick onto $4 \mathrm{H}-\mathrm{SiC}$ annealed at $1000^{\circ} \mathrm{C}$ during $1 \times 30 \mathrm{~min}$ and $3 \times 10 \mathrm{~min}$.

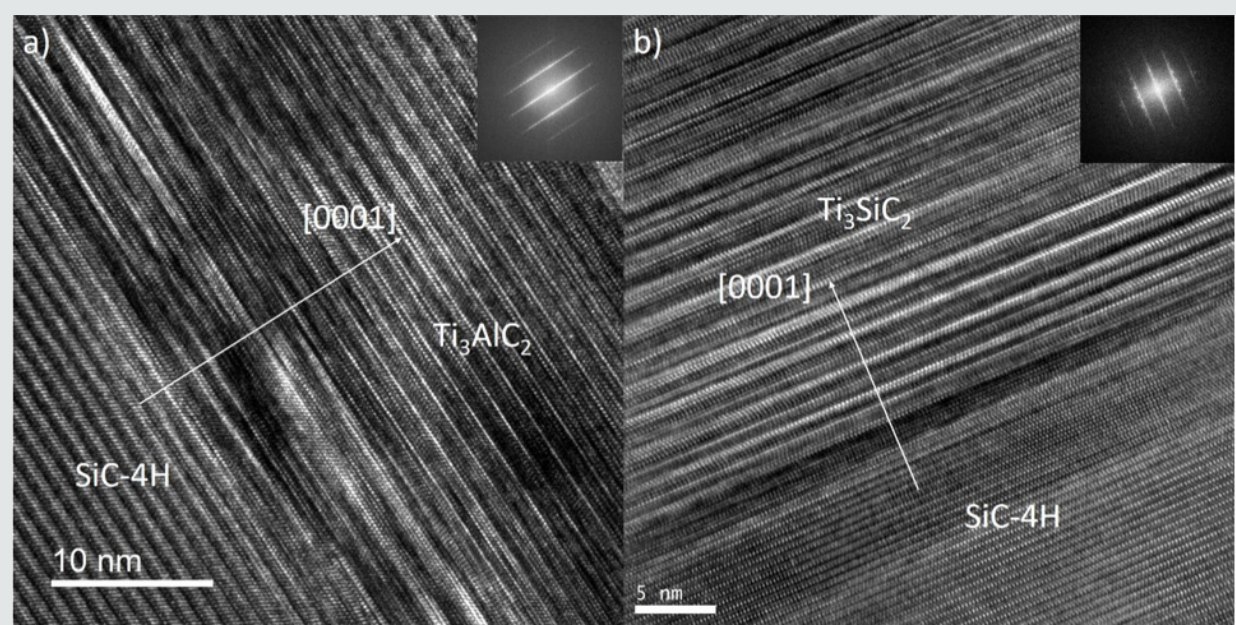

Figure 4: HRTEM micrography of $\mathrm{TiAl}_{2}-300 \mathrm{~nm}$ annealed at a) $800^{\circ} \mathrm{C}-1 \times 30 \mathrm{~min}$ and b) $1000^{\circ} \mathrm{C}-1 \times 30$ min and associated diffraction patterns. The diffraction patterns can be indexed using $\mathrm{SiC}-4 \mathrm{H}$ and respectively $\mathrm{Ti}_{3} \mathrm{AlC}_{2}, \mathrm{Ti}_{3} \mathrm{SiC}_{2}$ structures on $[10-$ $10]$ zone axis. 


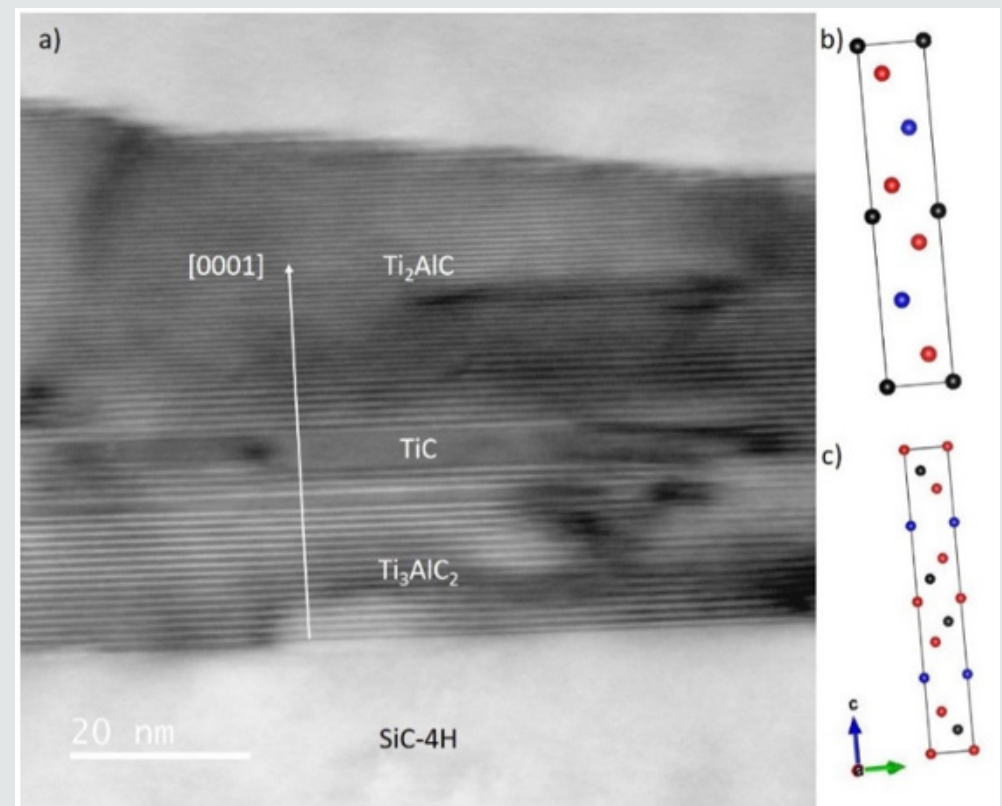

Figure 5: a) HRSTEM micrography of $\mathrm{TiAl}_{2}-300 \mathrm{~nm}$ annealed $1000^{\circ} \mathrm{C} 3 \times 10 \mathrm{~min}, \mathrm{~b}$ ) and c) represent respectively the $\mathrm{Ti}_{2} \mathrm{AlC}$ and $\mathrm{Ti}_{3} \mathrm{AlC}_{2}$ structure. Black, red and blue dots correspond respectively to $\mathrm{C}$, Ti and $\mathrm{Al}$ atoms.

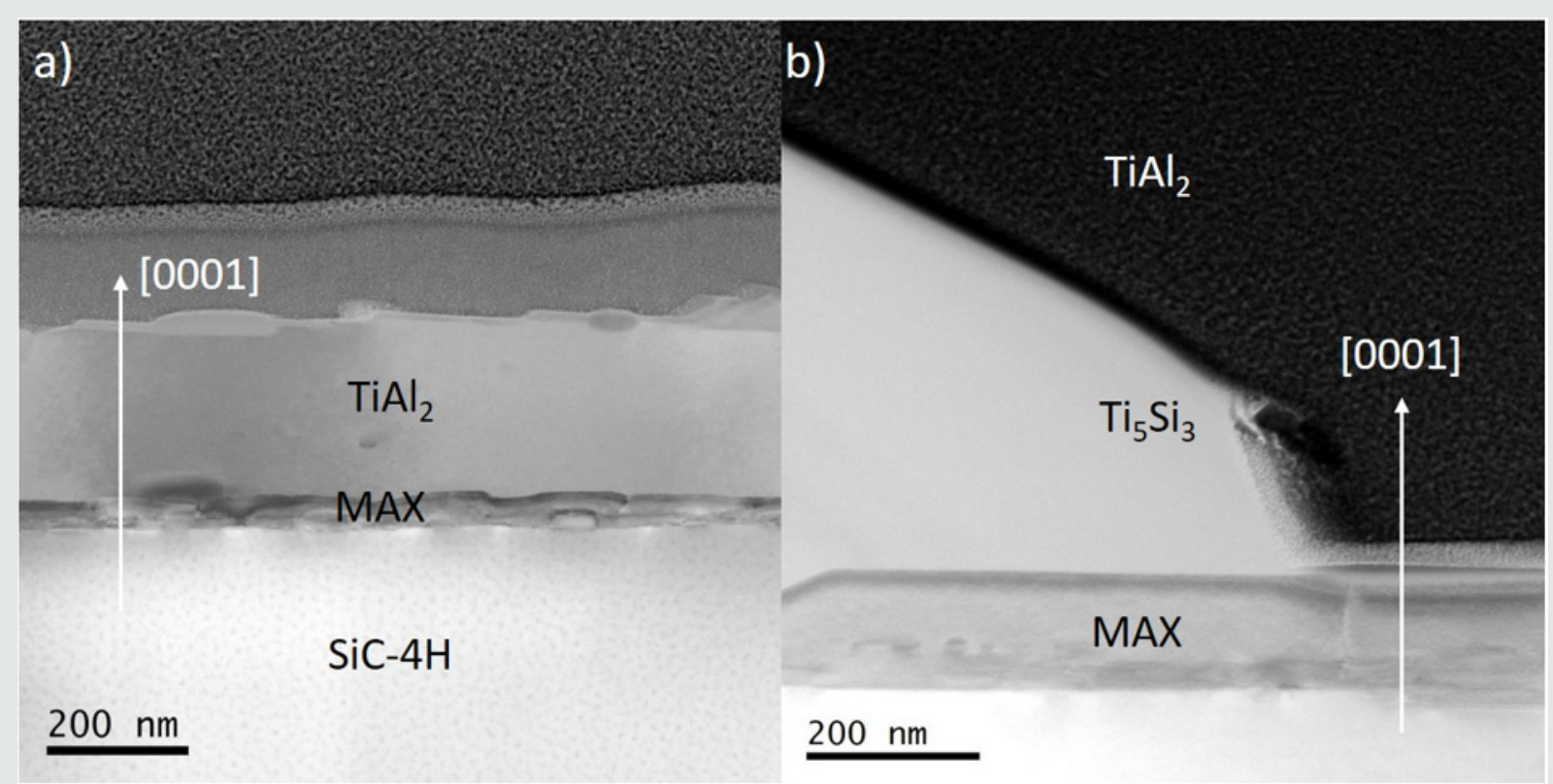

Figure 6: STEM micrographs of TiAl2 - 300nm annealed at $1000^{\circ} \mathrm{C}$ a) $3 \times 10 \mathrm{~min}$ and b) $1 \times 30 \mathrm{~min}$. The MAX phase stacking layer is respectively $80 \mathrm{~nm}$ and $150 \mathrm{~nm}$ thick.

\section{Discussion}

As shown Figures 2,3,4 the annealing of the $\mathrm{TiAl}_{2}$ layer leads to the formation of an epitaxial MAX phase thin film onto $\mathrm{SiC}-4 \mathrm{H}$ whatever successive runs used (long time or several successive short times). For $1 \times 30 \mathrm{~min}$ the structure of this MAX phase is $\mathrm{Ti}_{3} \mathrm{AlC}_{2}$ or $\mathrm{Ti}_{3} \mathrm{SiC}_{2}$ depending on annealing temperature, respectively for $800^{\circ} \mathrm{C}$ and for $1000^{\circ} \mathrm{C}$. The formation of 312 MAX phase at low temperature is very interesting and absolutely not expected, indeed, it has been showed that for bulk sample the 312 structure should be formed only at very-high temperature $[19,20]$. In the case of fast temperature increase, thermodynamical equilibrium isn't respect anymore. Thus, only thermodynamical consideration used in previous studies aren't enough anymore and kinetic effect couldn't be avoid. XRD and TEM experiments indicate that annealing process has an influence on MAX phase structure and properties. Moreover, the MAX phase thickness is also impacted. Indeed, for successive short annealing time, and consequently several cooling temporizations, the layer isn't as thick as the one long run annealing process sample. For multi-step annealing process we assume that the early stages of MAX phase formation have been already explained as follow:

$$
\mathrm{SiC}+\mathrm{TiAl}_{2} \rightarrow \mathrm{TiC}+(\mathrm{Al}, \mathrm{Si})_{1}
$$


which is in a good agreement with purely thermodynamic considerations [20]. This kind of reaction leads to an epitaxial growth. Then, the reaction continues with the second step:

$$
2 \mathrm{TiC}+\mathrm{Al} \rightarrow \mathrm{Ti}_{2} \mathrm{AlC}+\mathrm{C}
$$

leading to the formation of $\mathrm{Ti}_{2} \mathrm{AlC}$ and extra silicon atoms (Figure 7). We assume that $\mathrm{Si}$ segregates above the $\mathrm{Ti}_{2} \mathrm{AlC}$ and stay at the interface between the MAX phase and $\mathrm{TiAl}_{2}$ layer. Indeed, calculations indicate a fast kinetic diffusion of $\mathrm{Al}$ atoms in the $\mathrm{TiC}$ structure to form $\mathrm{Ti}_{2} \mathrm{AlC}$ [21]. Moreover, due to the fact that the $\mathrm{Ti}_{\mathrm{n}+1} \mathrm{SiC}_{\mathrm{n}}$ system does not have the 211 phase, the silicon cannot substitute $\mathrm{Al}$ species in the $\mathrm{Ti}_{2} \mathrm{AlC}$ MAX phase [22]. During the cooling, the Si reacts with unconsumed $\mathrm{TiAl}_{2}$ to form a very stable
$\mathrm{Ti}_{5} \mathrm{Si}_{3}$ structure. In the same time, we assume that the upper $\mathrm{TiAl}_{2}$, not yet involved in these two previous steps, will crystallize. Thus, the formation of $\mathrm{Ti}_{2} \mathrm{AlC}$ MAX phase is a two steps reaction. After cooling, the stacking of all phases is shown (Figure 7), from the top to the interface : polycristalline $\mathrm{Ti}_{3} \mathrm{Al}_{2} / \mathrm{Ti}_{5} \mathrm{Si}_{3} / \mathrm{Ti}_{2} \mathrm{AlC} / \mathrm{SiC}$. When the annealing is resumed, Ti element has to diffuse toward $\mathrm{SiC}$ interface to create $\mathrm{TiC}$, going through MAX phase or MAX phase and $\mathrm{Ti}_{5} \mathrm{Si}_{3}$ either if $\mathrm{Ti}$ become from $\mathrm{Ti}_{3} \mathrm{Al}$ or $\mathrm{Ti}_{5} \mathrm{Si}_{3}$. We assume that the stability of MAX phase is enough strong to unconsidered creation of TiC with Ti originated from MAX Phase. By this way the Ti diffusion process is slow, thus the $\mathrm{TiC}$ formation is a very slow process. However, it occurs leading to the following reaction (Figure 7):

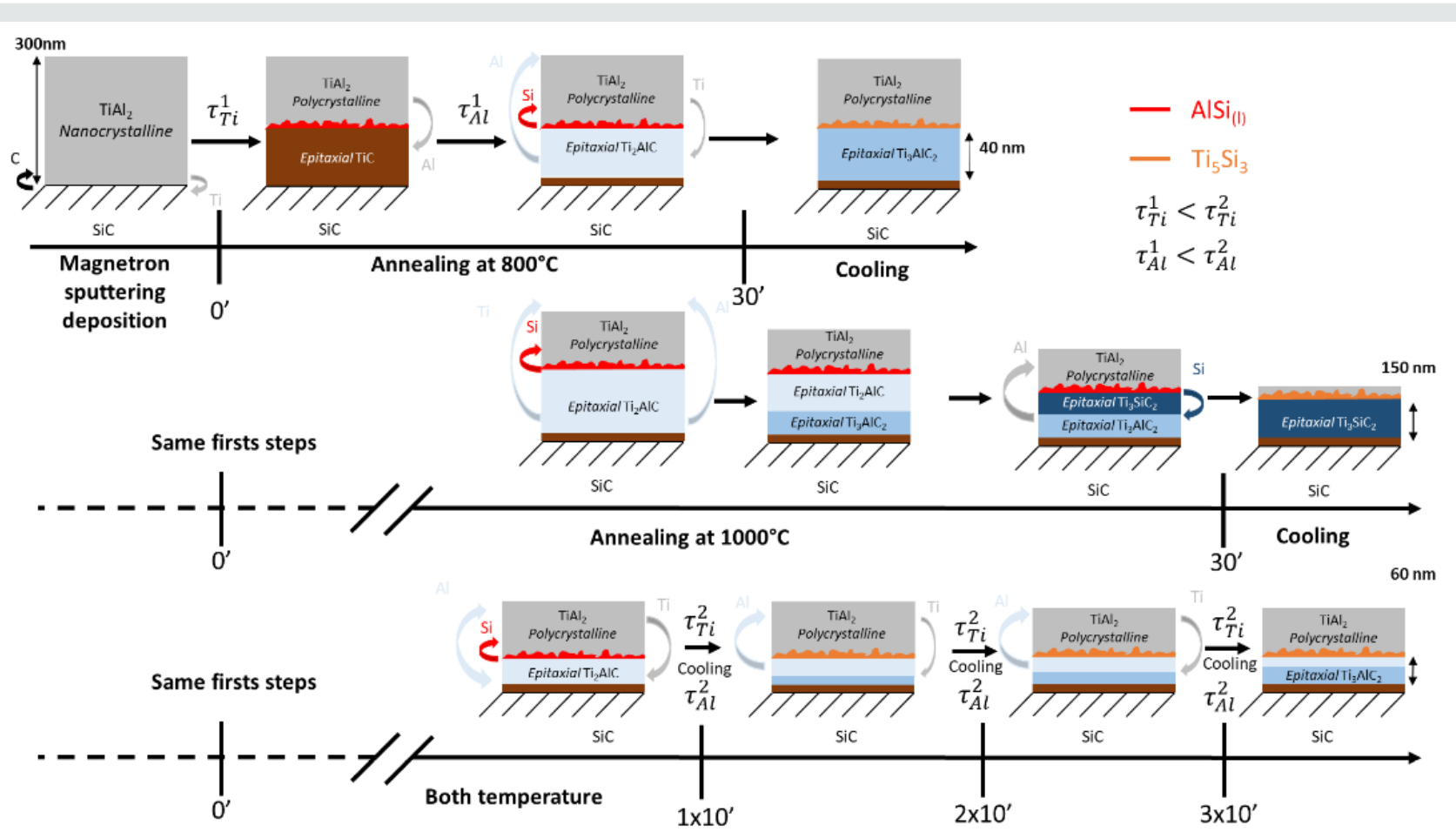

Figure 7: Representation of the mechanisms involved as a function of the temperature and the number of annealing steps $(1 \times 30 \mathrm{~min}$ or $3 \times 10 \mathrm{mn})$, with $\tau^{1}{ }_{(\mathrm{Ti}, \mathrm{Al})}$ and $\mathrm{\tau}^{2}{ }_{(\mathrm{Ti}, \mathrm{Al})}$ represent the diffusion time constant of $\mathrm{Ti}$ or $\mathrm{Al}$ element from the Fick equations for the one annealing step $(1 \times 30 \mathrm{~min})$ and several steps $(3 \times 10 \mathrm{~min})$ respectively.

The described mechanisms occur for both, $800^{\circ} \mathrm{C}$ and $1000^{\circ} \mathrm{C}$, but considering that diffusion mechanisms increase with temperature, we assume that Ti diffusion process is higher for $1000^{\circ} \mathrm{C}$ leading to a thicker $\mathrm{Ti}_{3} \mathrm{AlC}_{2}$ than for $800^{\circ} \mathrm{C}$, which is in a good agreement with XRD (Figure 2). Indeed the 312/211 intensity ratio is much higher for $1000^{\circ} \mathrm{C}$ than for $800^{\circ} \mathrm{C}$. Moreover, considering TEM observations, and due to the high theoretical intensity diffraction of (1014) MAX phase plane we considered that the formation following this orientation isn't really representative of MAX phase growth mechanisms. For one-single annealing process, we consider that the first reactions are similar. Moreover, considering that the thickness of MAX phase formed is thinner for annealing process having cooling temporization, we can traduce this information by a longer diffusion kinetic (longer diffusion time or lengths) of diffusing species. Without cooling, Ti has to diffuse only in $\mathrm{TiAl}_{2}$ and first MAX phase monolayers in growth indeed Nowadays we don't know if the diffusion of $\mathrm{Al}$ is during the cooling or during annealing. If the Al diffuses during cooling only, Ti should diffuse only in $\mathrm{TiAl}_{2}$.Unfortunately, diffusion time and length of $\mathrm{Ti}$ in different phases involved is not known. So, the first hypothesis is the increase of Ti diffusion time and length in $\mathrm{Ti}_{5} \mathrm{Si}_{3}+\mathrm{Ti}_{2} \mathrm{AlC}$ than in $\mathrm{TiAl}_{2}+\mathrm{Ti}_{2} \mathrm{AlC}$. The second hypothesis is the same concerning $\mathrm{Al}$ diffusion kinetics. Thus, the $\mathrm{Ti}_{2} \mathrm{AlC}$ completely turns into $\mathrm{Ti}_{3} \mathrm{AlC}_{2}$. The XRD and TEM experiments show after 1 x $30 \mathrm{~min}$ that for $800^{\circ} \mathrm{C}$ the $\mathrm{Ti}_{3} \mathrm{AlC}_{2}$ MAX phase is formed while for $1000^{\circ} \mathrm{C}$ after the MAX phase formed is $\mathrm{Ti}_{3} \mathrm{SiC}_{2}$. By this way, we assume that at $1000^{\circ} \mathrm{C}$ the Si can diffuse through the $\mathrm{Ti}_{3} \mathrm{AlC}_{2}$ structure and can substitutes $\mathrm{Al}$ atoms of $\mathrm{Ti}_{3} \mathrm{AlC}_{2}$ considering the following reaction:

$$
\mathrm{Ti}_{3} \mathrm{AlC}_{2}+\mathrm{Si} \rightarrow \mathrm{Ti}_{3} \mathrm{SiC}_{2}+\mathrm{Al}
$$


This kind of phenomena has been already observed with $\mathrm{Au}$ and $\mathrm{Ti}_{3} \mathrm{SiC}_{2}$ [23]. Finally during the cooling the $\mathrm{Ti}_{5} \mathrm{Si}_{3}$ structure is formed leading to the stacking: $\mathrm{SiC} / 312 \mathrm{MAX}$ phase / $\mathrm{Ti}_{5} \mathrm{Si}_{3}$ / $\mathrm{TiAl}_{2}$ (Figure 7) Representation of the mechanisms involved as a function of the temperature and the number of annealing steps (1x30min or $3 \times 10 \mathrm{mn})$, with $\left.\tau^{1}(T i, A l)\right)$ and $\tau^{2}(T i, A l)$ represent the diffusion time constant of $\mathrm{Ti}$ or $\mathrm{Al}$ element from the Fick equations for the one annealing step (1x30 min) and several steps (3x10min) respectively.

\section{Conclusion}

In this paper we demonstrated the possibility to synthesize $\mathrm{Ti}_{2} \mathrm{AlC}, \mathrm{Ti}_{3} \mathrm{AlC}_{2}$ or $\mathrm{Ti}_{3} \mathrm{SiC}_{2}$ thin-film onto $\mathrm{SiC}-4 \mathrm{H}$ using a common two-steps method by tailoring temperature and time running indeed, for similar thermal cumulative energy (30min at setpoint temperature) the obtained MAX phase structure depends on the annealing process. At low temperature $\left(800^{\circ} \mathrm{C}\right)$ : one single-step process leads to the formation of $\mathrm{Ti}_{3} \mathrm{AlC}_{2} \mathrm{MAX}$ phase while multistep process leads to the formation of $\mathrm{Ti}_{2} \mathrm{AlC}$ MAX phase with a few quantity of unepitaxial $\mathrm{Ti}_{3} \mathrm{AlC}_{2}$. At high temperature $\left(1000^{\circ} \mathrm{C}\right)$ : one single step leads to the formation of very pure $\mathrm{Ti}_{3} \mathrm{SiC}_{2}$ while multistep process leads to the formation of a $\mathrm{Ti}_{3} \mathrm{AlC}_{2}-\mathrm{Ti}_{2} \mathrm{AlC}$ mixture. We assume that similarly to low temperature the multi-step process decreases the kinetic of the reaction leading to an incomplete transformation of $\mathrm{Ti}_{3} \mathrm{AlC}_{2}-\mathrm{Ti}_{2} \mathrm{AlC}$ to $\mathrm{Ti}_{3} \mathrm{SiC}_{2}$.

\section{Acknowledgement}

The authors would like to acknowledge H. Bahsoun for the TEM thin foil preparation. This work partially pertains to the French Government program "Investissements d'Avenir" (LABEX INTERACTIFS, reference ANR-11-LABX-0017-01). This work has been partially supported by "Nouvelle Aquitaine" Region and by European Structural and Investment Funds (ERDF reference: P-2016-BAFE-94/95).

\section{References}

1. P Eklund, M Beckers, U Jansson, H Hogberg, L Hultman (2010) The $\mathrm{Mn}+1 \mathrm{AXn}$ phases: Materials science and thin film processing, Thin Solid Films 518(8): 1851-1878.

2. M Barsoum (2013) MAX Phases: Properties of Machinable Ternary Carbides and Nitrides, wiley \& so Edition.

3. MW Barsoum (2000) The MN+1AXN Phases: A New Class of Solids 28: 201-281.

4. T Lapauw, J Halim, J Lu, T Cabioc'h, L Hultman, et al. (2016) Synthesis of the novel Zr3AlC2 MAX phase, Journal of the European Ceramic Society 36(3): 943-947.

5. J Gonzalez Julian, J Llorente, M Bram, M Belmonte, O Guillon, Novel Cr2AlC MAX-phase/SiC fiber composites: Synthesis, processing and tribological response. Journal of the European Ceramic Society, pp. 467475 .

6. MW Barsoum, M Radovic (2011) Elastic and Mechanical Properties of the MAX Phases, Annual Review of Materials Research 41 (1): 195-227.

7. T Lapauw, AK Swarnakar, B Tunca, K Lambrinou, J Vleugels (2018) Nanolaminated ternary carbide (MAX phase) materials for high temperature applications. International Journal of Refractory Metals and Hard Materials 72: 51-55.

8. T Yang, C Wang, CA Taylor, X Huang, Q Huang, et al. (2014) The structural transitions of $\mathrm{Ti}_{3} \mathrm{AlC}_{2}$ induced by ion irradiation. Acta Materialia 65: 351359.

9. H Zhang, R Su, L Shi, DJ O'Connor, et al. (2018) The damage evolution of He irradiation on $\mathrm{Ti}_{3} \mathrm{SiC}_{2}$ as a function of annealing temperature. Journal of the European Ceramic Society 38(4): 1253-1264.

10. HH Shen, FZ Li, HB Zhang, SM Peng, et al. (2017) Effects of Xe+ irradiation on $\mathrm{Ti}_{3} \mathrm{SiC}_{2}$ at $\mathrm{RT}$ and $500 \mathrm{C}$. Journal of the European Ceramic Society 37 (2): 855-858.

11.Z Sun, Y Zhou, M Li (2001) High temperature oxidation behavior of Ti3SiC2-based material in air. Acta Materialia 49(20): 4347-4353.

12. H Fashandi, M Andersson, J Eriksson, J Lu, K Smedfors, et al. (2015), Single-step synthesis process of Ti3SiC2 ohmic contacts on $4 \mathrm{H}-\mathrm{SiC}$ by sputter-deposition of Ti. Scripta Materialia 99: 53-56.

13. A Drevin Bazin, JF Barbot, M Alkazaz, T Cabioch, MF Beaufort (2012) Epitaxial growth of $\mathrm{Ti} 3 \mathrm{SiC} 2$ thin films with basal planes parallel or orthogonal to the surface on_-SiC. Applied Physics Letters 101(2): 2-5.

14. T Lapauw, K Lambrinou, T Cabioc'h, J Halim, J Lu, et al. (2016) Synthesis of the new MAX phase Zr2AlC. Journal of the European Ceramic Society 36(8): 1847-1853.

15. R Su, H Zhang, DJ O’Connor, L Shi, X Meng, et al. (2016) Deposition and characterization of Ti2AlC MAX phase and Ti3AlC thin films by magnetron sputtering. Materials Letters 179: 194-197.

16. R Shu, F Ge, F Meng, P Li, J Wang, et al. (2017) One-step synthesis of polycrystalline V2AlC thin films on amorphous substrates by magnetron co-sputtering. Vacuum 146: 106-110.

17. J Nicolai, C Furgeaud, B Fonrose, C Bail, M Beaufort (2017) Formation mechanisms of $\mathrm{Ti}_{2} \mathrm{AlC}$ MAX phase on $\mathrm{SiC}-4 \mathrm{H}$ using magnetron sputtering and post-annealing. Materials \& Design, pp. 209-2013

18. RM Langford, C Clinton (2004) In situ lift-out using a FIB-SEM system. Micron 35(7): 607-611.

19. MW Barsoum (2000) Comment on 'Reaction layers around SiC particles in Ti: An electron microscopy study', Scripta Materialia 43(3): 285-286.

20. I Gotman, EY Gutmanas, P Mogilevsky (1993) Interaction between SiC and Ti powder. Journal of Materials Research 8(10): 2725-2733.

21.SC Middleburgh, GR Lumpkin, DRiley (2013) Accommodation, accumulation, and migration of defects in $\mathrm{Ti}_{3} \mathrm{SiC}_{2}$ and $\mathrm{Ti}_{3} \mathrm{Als}$ MAX phases. Journal of the American Ceramic Society 96(10): 3196-3201.

22. VJ Keast, S Harris, DK Smith (2009) Prediction of the stability of the Mn+1AXn phases from first principles, Physical Review B 80 (21): 214113.

23. H Fashandi, M Dahlqvist, J Lu, J Palisaitis, SI Simak et al. (2017) Synthesis of $\mathrm{Ti}_{3} \mathrm{AuC}_{2}, \mathrm{Ti}_{3} \mathrm{Au}_{2} \mathrm{C}_{2}$ and $\mathrm{Ti}_{3} \mathrm{IrC}_{2}$ by noble metal substitution 
CC (P) This work is licensed under Creative

To Submit Your Article Click Here: $\quad$ Submit Article

DOI: $10.32474 / M A M S .2019 .01 .000117$

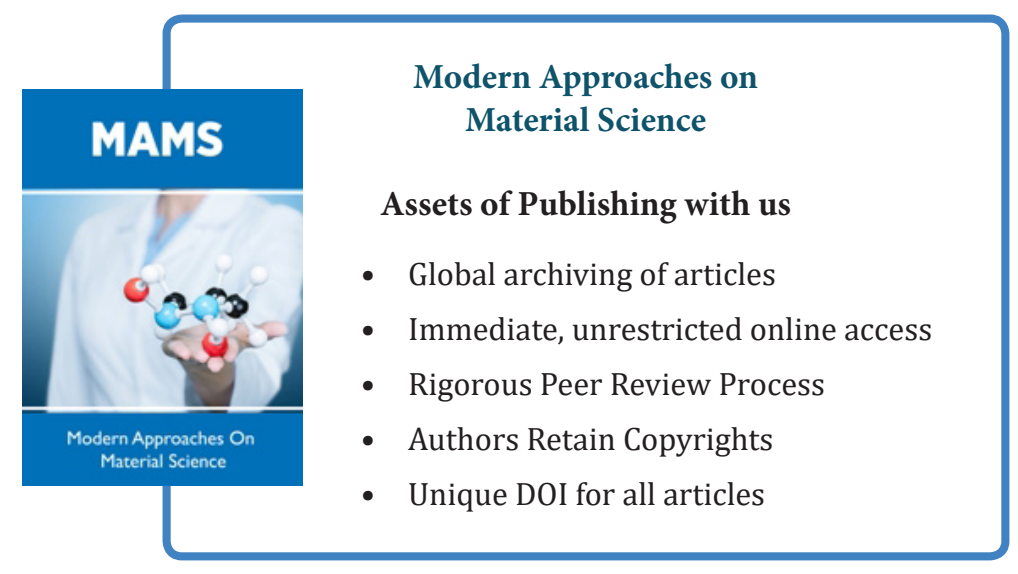

